\title{
Congenital nasal pyriform aperture stenosis
}

\author{
Luana A. Stanescu • Gisele E. Ishak
}

Received: 2 August 2010 /Accepted: 30 August 2010/Published online: 9 October 2010

(C) Springer-Verlag 2010

Congenital pyriform aperture stenosis represents an unusual cause of nasal obstruction in neonates and is caused by overgrowth of the nasal process of the maxilla. A pyriform aperture width of less than $11 \mathrm{~mm}$ (Fig. 1) is diagnostic [1]. Its clinical presentation is similar to that of bilateral choanal

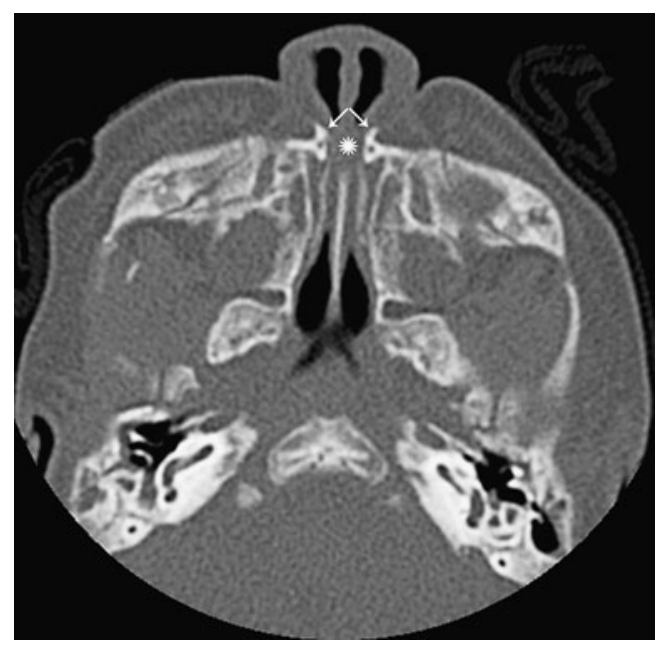

Fig. 1 Axial CT at the level of the inferior meatus in a one-month old male. There is pyriform aperture narrowing with a maximum width of $5 \mathrm{~mm}$ (asterisk). There is bony overgrowth of the nasal processes of the maxilla (arrows) atresia and may range from mild nasal obstruction to lifethreatening asphyxia. Up to $63 \%$ of the patients have a solitary median incisor (Fig. 2), thought to represent a mild form of the holoprosencephaly spectrum [2], in which case MRI of the brain and chromosomal analysis are also indicated.

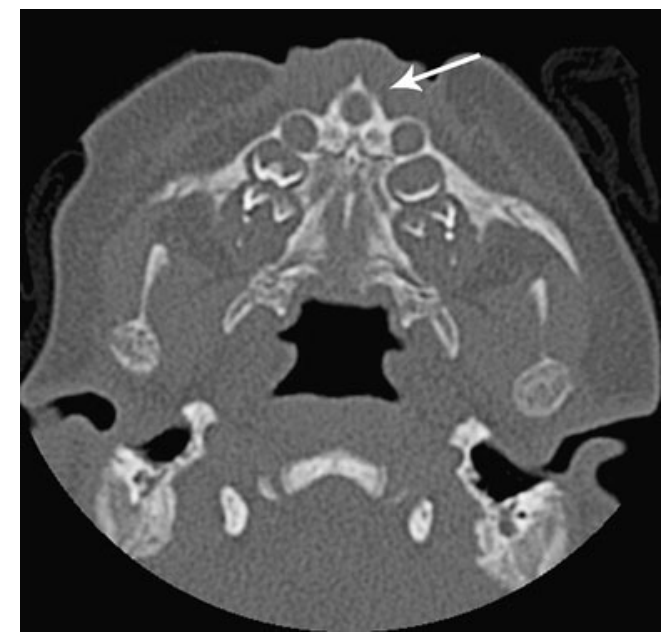

Fig. 2 Axial CT through the palate shows a single median incisor bud (arrow)

\section{References}

1. Belden CJ, Mancuso AA, Schmalfuss IM (1999) CT features of congenital nasal piriform aperture stenosis: initial experience. Radiology 213:495-501

2. Lo FS, Lee YJ, Lin SP et al (1998) Solitary maxillary central incisor and congenital nasal pyriform aperture stenosis. Eur $\mathrm{J}$ Pediatr 157:39-44
L. A. Stanescu $(\bowtie) \cdot$ G. E. Ishak

Department of Radiology, Seattle Children's Hospital,

4800 Sand Point Way NE,

Seattle, WA 98105, USA

e-mail: stanescu@u.washington.edu 